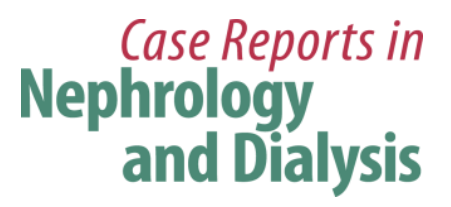

Case Rep Nephrol Dial 2018;8:20-24

DOI: $10.1159 / 000485244$

Published online: January 31, 2018

(C) 2018 The Author(s)

Published by S. Karger AG, Basel

www.karger.com/cnd

This article is licensed under the Creative Commons Attribution-NonCommercial 4.0 International License (CC BY-NC) (http://www.karger.com/Services/OpenAccessLicense). Usage and distribution for commercial purposes requires written permission.

\title{
Oxcarbazepine Therapy for Complete Central Diabetes Insipidus
}

\author{
Basmah Abdallah $^{a} \quad$ Spencer Hodgins ${ }^{a} \quad$ Daniel Landry ${ }^{a, b}$ \\ Michael O'Shea ${ }^{a, b} \quad$ Gregory Braden ${ }^{a, b}$
}

${ }^{a}$ Department of Medicine, Baystate Medical Center, Tufts University School of Medicine, Springfield, MA, USA; ${ }^{b}$ Division of Nephrology, Baystate Medical Center, Tufts University School of Medicine, Springfield, MA, USA

\section{Keywords}

Oxcarbazepine $\cdot$ Hyponatremia $\cdot$ Diabetes insipidus

\begin{abstract}
Oxcarbazepine and carbamazepine cause hyponatremia by unknown mechanisms. We describe a patient with complete central diabetes insipidus and seizures who developed worsening hyponatremia when her dose of oxcarbazepine was increased. The patient maintained a normal serum sodium level and has had appropriately concentrated urine for 5 years on just oxcarbazepine, despite undetectable antidiuretic hormone $(A D H)$ levels. This suggests that oxcarbazepine (or one of its metabolites) may stimulate collecting tubule V2 receptor- $G$ protein complex independent of $A D H$, resulting in increased renal tubular water reabsorption. Oxcarbazepine may be useful as an alternative therapy for patients with central diabetes insipidus.

(C) 2018 The Author(s)

Published by S. Karger AG, Basel
\end{abstract}




\section{Introduction}

We describe a 39-year-old female with a history of complete central diabetes insipidus (CDI) who developed severe hyponatremia after an increase in oxcarbazepine dose. Her unique case provides new insights into the physiologic mechanisms of oxcarbazepineinduced hyponatremia and supports the use of oxcarbazepine as a novel treatment for CDI.

\section{Case Report}

A 39-year-old female suffered a traumatic brain injury from a motor vehicle accident in 2009, following which she developed a generalized tonic-clonic seizure disorder and complete CDI. She had undetectable antidiuretic hormone (ADH) levels and an appropriate hydrosmotic response to DDAVP during a water deprivation test in June 2009. Seizures were controlled by oxcarbazepine $600 \mathrm{mg}$ twice daily and CDI was controlled by intranasal DDAVP, $10 \mu \mathrm{g}$ twice daily.

The patient developed uncontrolled grand mal seizures in July 2011. Her serum sodium (SNa) level was $133 \mathrm{mEq} / \mathrm{L}$ (mmol/L) and her oxcarbazepine level was $21 \mu \mathrm{g} / \mathrm{mL}$ (therapeutic range $10-35 \mu \mathrm{g} / \mathrm{mL}$ ). The oxcarbazepine dose was initially increased to $750 \mathrm{mg}$ twice daily and then to $900 \mathrm{mg}$ twice daily after she developed breakthrough seizures. The SNa fell to $131 \mathrm{mEq} / \mathrm{L}$ (Table 1). DDAVP was subsequently discontinued, but the SNa level continued to decline, reaching a nadir of $121 \mathrm{mEq} / \mathrm{L}$ on hospital day 9 (Table 1). Serum cortisol and TSH levels were normal. She was treated with $3 \%$ saline followed by fluid restriction. The SNa increased to $138 \mathrm{mEq} / \mathrm{L}$ in 2 days and she was discharged off DDAVP, taking just oxcarbazepine $900 \mathrm{mg}$ twice daily. An ADH level was undetectable $(<0.5 \mathrm{pg} / \mathrm{mL}$ ) (Table 1$)$.

A repeat serum ADH level was obtained 2 weeks following discharge and it was again undetectable $(<0.5 \mathrm{pg} / \mathrm{mL})$, which correlated with a serum osmolality of $288 \mathrm{mosm} / \mathrm{kg}$ and SNa of $137 \mathrm{mEq} / \mathrm{L}$. She maintained normal SNa levels on only oxcarbazepine. She did develop mild hyponatremia ( $\mathrm{SNa}$ of $130 \mathrm{mEq} / \mathrm{L}$ ) 4 months later while her oxcarbazepine level was above normal at $42 \mu \mathrm{g} / \mathrm{mL}$ (therapeutic range $10-35 \mu \mathrm{g} / \mathrm{mL}$ ) without other medication changes. Five years later, the patient has remained off DDAVP with oxcarbazepine as the sole therapy controlling her epilepsy and CDI.

\section{Discussion}

The development of severe hyponatremia in this patient was completely unexpected and atypical of patients with CDI who usually present with polyuria and hypernatremia. This finding alerted us to the possibility of the antidiuretic effects of oxcarbazepine, which did not occur at lower doses but became apparent, however, at $900 \mathrm{mg}$ twice daily. Here we explore the potential underlying mechanisms of these effects.

Given the structural similarity between carbamazepine and oxcarbazepine, it has been proposed that these agents decrease the SNa by similar mechanisms. The antidiuretic effect of carbamazepine was first described in 1966 when a beneficial effect of carbamazepine in 


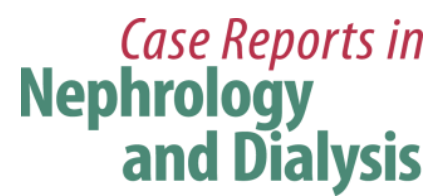

Case Rep Nephrol Dial 2018;8:20-24

DOI: $10.1159 / 000485244$

(c) 2018 The Author(s). Published by S. Karger AG, Basel www.karger.com/cnd

Abdallah et al.: Oxcarbazepine Therapy for Complete Central Diabetes Insipidus

controlling polyuria was observed in a patient with CDI [1]. In a cross-sectional study the frequency of hyponatremia was greater with oxcarbazepine than carbamazepine [2].

There have been several proposed mechanisms for carbamazepine-induced hyponatremia. Only one study reported an increase in plasma ADH activity during carbamazepine therapy [3]. However, this study utilized a bioassay method for plasma ADH and not the currently used radioimmunoassays. In contrast, all other studies described a decrease in ADH levels during carbamazepine therapy, and they proposed that the drug may directly stimulate the ADH receptor site [4]. Other possible mechanisms of carbamazepine-induced hyponatremia include prolongation of ADH half-life, carbamazepine-enhanced sensitivity of renal collecting tubules to $\mathrm{ADH}$, and a resetting of the hypothalamic osmotic threshold for $\mathrm{ADH}$ release $[5,6]$. In a prospective study of 11 epileptic and 10 healthy patients treated with oxcarbazepine, Sachdeo et al. [7] showed impaired free water clearance and a decrease in SNa levels with no increase in ADH levels during free water loading experiments. They concluded that oxcarbazepine likely increases the hydrosmotic sensitivity of collecting tubules to ADH or directly stimulates collecting tubule water reabsorption. In addition, after hyponatremia was induced by oxcarbazepine or carbamazepine in normal human volunteers, ADH levels were $<0.5 \mathrm{pg} / \mathrm{mL}$, but a specific V2 receptor antagonist enhanced free water clearance and the SNa returned to normal. These authors concluded that oxcarbazepine can induce renal water retention in the presence of very low levels of ADH undetectable by current assays [8].

Moreover, in a recent study of rat inner medullary collecting ducts, carbamazepine was shown in vitro to enhance free water permeability in the absence of ADH through an increase in aquaporin-2 (AQP2) expression in both normal collecting ducts and in collecting ducts in rats with lithium-induced nephrogenic DI via action on the V2 receptor-G protein complex [9]. Similar results were demonstrated by these same investigators in vivo, where administration of lithium chloride in rats reduced the expression of AQP2 by approximately $50 \%$ when compared to controls. This reduction in AQP2 expression was reversed by approximately $20 \%$ in the group that received carbamazepine plus lithium chloride [9]. In summary, these studies suggest that carbamazepine and oxcarbazepine enhance water reabsorption in renal collecting tubules by increasing AQP2 expression either independent of $\mathrm{ADH}$ or in the presence of very low levels of $\mathrm{ADH}$ undetectable by current assays. Of particular interest, toad bladder studies with carbamazepine failed to show any antidiuretic activity, lending credence to the idea that a metabolite of carbamazepine/oxcarbazepine is actually responsible for this antidiuretic effect [10].

Our case report is the first clinical evidence to show that oxcarbamazepine can induce hyponatremia in a human subject either independent of ADH or at clinically undetectable ADH levels and that it may be an alternative therapy to DDAVP in patients with CDI. Whether or not oxcarbazepine could also be a therapy for nephrogenic diabetes insipidus (NDI) needs to be further examined. The work by de Bragança et al. [9] showing partial reversal of lithium-induced NDI with carbamazepine in rats suggests that these agents could be utilized in patients with lithium-induced NDI.

In summary, our patient with complete CDI previously dependent upon DDAVP developed oxcarbazepine-induced hyponatremia. Her CDI was safely managed with oxcarbazepine in place of DDAVP. Our study refutes the long-standing proposed mechanism of classic 


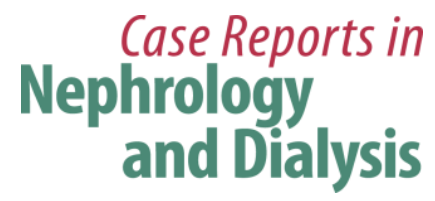

Case Rep Nephrol Dial 2018;8:20-24

SIADH as the cause of oxcarbazepine-induced hyponatremia and provides a novel alternative therapy for patients with CDI.

\section{Statement of Ethics}

The research, data review, and analysis in this paper were performed in accordance with the ethical standards of the Declaration of Helsinki of 1975 and its revised doctrine in 2000 .

\section{Disclosure Statement}

The authors have no conflicts of interest to declare.

\section{References}

1 Braunhofer J, Zicha L: Does Tegretal offer new possibilities of therapy in several neurologic and endocrine diseases?. A clinical electroencephalographic and thin-layer chromatographic study (in German). Med Welt 1966;36:1875-1880.

- Nielsen OA, Johannessen AC, Bardrum B: Oxcarbazepine-induced hyponatremia, a cross-sectional study. Epilepsy Res 1988;2:269-271.

- Frahm H, Smejkal E, Kratzenstein R: Demonstration of serum ADH activities in hypophysectomy patients with polyuria and polydipsia and subjects with diabetes insipidus under the influence of an antidiuretically active psychotropic antiepilepticum [5-carbamyl-5-H-dibenzo-(b, f)azepin = Tegretal] (in German). Verh Dtsch Ges Inn Med 1969;75:777-779.

-4 Meinders AE, van Leeuwen AM, Borst JG, Cejka V: Paradoxical diuresis after vasopressin administration to patients with neurohypophyseal diabetes insipidus treated with chlorpropamide, carbamazepine or clofibrate. Clin Sci Mol Med 1975;49:283-290.

-5 Van Amelsvoort T, Bakshi R, Devaux CB, Schwabe S: Hyponatremia associated with carbamazepine and oxcarbazepine therapy: a review. Epilepsia 1994;35:181-188.

6 Stephens WP, Coe JY, Baylis PH: Plasma arginine vasopressin concentrations and antidiuretic action of carbamazepine. Br Med J 1978;1:1445-1447.

7 Sachdeo RC, Wasserstein A, Mesenbrink PJ, D’Souza J: Effects of oxcarbazepine on sodium concentration and water handling. Ann Neurol 2002;51:613-620.

8 Bichet DG, Remillard G, Madore F, et al: Correction of hyponatremia by a single oral dose of $75 \mathrm{mg}$ of the non-peptide V2 antagonist VPA-985 in hyponatremia patients receiving carbamazepine or oxcarbazepine. J Am Soc Nephrol 1999;10:119A.

9 de Bragança AC, Moyses ZP, Magaldi AJ: Carbamazepine can induce kidney water absorption by increasing aquaporin 2 expression. Nephrol Dial Transplant 2010;25:3840-3845.

10 Meier KE, Mendoza SA: Effects of carbamazepine on the water permeability and short-circuit current of the urinary bladder of the toad and the response to vasopressin, adenosine $3{ }^{\prime}, 5^{\prime}$-cyclic phosphate and theophylline. J Pharmacol Exp Ther 1977;200:95-100. 
Table 1. A summary of medication adjustments and associated pertinent serum and urine laboratory values

\begin{tabular}{|c|c|c|c|c|c|c|c|c|c|}
\hline & Admission & Day 1 & Day 3 & Day 8 & Day 9 & Day 10 & Day 12 & Day 13 & Day 27 \\
\hline OXC dose, mg b.i.d. & 600 & 750 & 900 & 900 & 900 & 900 & 900 & 900 & 900 \\
\hline DDAVP dose, $\mu$ g b.i.d. & 10 & 10 & 10 & 10 & none & none & none & none & none \\
\hline $\mathrm{SNa}, \mathrm{mEq} / \mathrm{L}$ & 133 & 133 & 131 & 127 & 121 & 133 & 137 & 139 & 137 \\
\hline SOsm, mosm $/ \mathrm{kg}$ & & 285 & & & & & 285 & 294 & 288 \\
\hline $\mathrm{ADH}, \mathrm{pg} / \mathrm{mL}$ & & & & & & $<0.05$ & & & $<0.05$ \\
\hline UOsm, mosm $/ \mathrm{kg}$ & & & & & 302 & 204 & 268 & 805 & \\
\hline UNa mEq/L & & & & & 62 & & $<10$ & 22 & \\
\hline
\end{tabular}

OXC, oxcarbazepine; b.i.d., twice daily; SNa, serum sodium; SOsm, serum osmolality; ADH, antidiuretic hormone; UOsm, urine osmolality; UNa, urine sodium.. 